\title{
Estratégias do fantástico em Sheridan Le Fanu, Lygia Fagundes Telles e Rui Herbon
}

\section{Strategies of the Fantastic in Sheridan Le Fanu, Lygia Fagundes Telles and Rui Herbon}

\author{
Maria JoÃo Simões [mjsimoes@fl.uc.pt] \\ CLP - Universidade de Coimbra, Portugal
}

\section{RESUMO}

Este texto visa comparar as diferenças estratégicas e os matizes componenciais do modo fantástico utilizados para instaurar o efeito de estranheza característico desta categoria estética em contos de Sheridan Le Fanu, Lygia Fagundes Telles e Rui Herbon. Partindo de algumas questões teóricas levantadas pelos estudiosos do fantástico e atentando nos pontos comuns e/ou nas divergências manifestadas em diversos posicionamentos teóricos, analisam-se os procedimentos escolhidos pelos autores para subverterem a ficcionalidade mimética seguidora das convenções realistas. Atenta-se ainda em certos efeitos estético-emotivos alcançados através dos protocolos ficcionais que o fantástico implementa para cativar o público leitor.

\section{Palavras-chave}

Fantástico; categoria estética; modo; estranhamento; neofantástico

\begin{abstract}
In this paper aims, the main objective is to compare strategic differences and componential nuances perceived in the fantastic mode that implement the strangeness which characterizes Sheridan Le Fanu, Lygia Fagundes Telles e Rui Herbon short stories. Based on theoretical questions raised by fantastic theorists, in their common and/or divergent approaches, the procedures and strategies chosen by the authors to subvert mimetic or realist fictionality will be analyzed. The aesthetic and emotional effects obtained through fictional protocols to captivate the public will also be considered.
\end{abstract}

\section{KEYWORDS}

Fantastic mode; aesthetic category; strangeness

RECEBIDO 2019-04-20; ACEITE 2019-06-30 


\section{Preâmbulo}

A famosa frase publicitária de Pessoa "Primeiro estranha-se. Depois, entranha-se" pode aplicarse ao gosto pela literatura fantástica: a literatura fantástica cativa-nos, prende-nos, absorve-nos à medida que vamos lendo mais narrativas fantásticas. Sem deixar de considerar a criança que há sempre em nós, talvez o maravilhoso que nos deslumbrou na infância e a fantasia que nos preencheu a adolescência nos tenham preparado para desenvolvermos, posteriormente, o gosto pelo fantástico e para nos deixarmos cativar por aquilo que Arnaud Huftier designa por "efeitos de fantástico" (Bozzetto et Huftier 2004: 24). Ora, há muito que os críticos se interrogam sobre o modo como surge esta pregnância do fantástico e como ela se processa. É ilustrativo a este propósito o título da obra La séduction de l'étrange de Louis Vax, que sugere bem a capacidade atrativa do fantástico. Publicada originalmente em 1965, nesta obra o autor adota uma abordagem influenciada pela psicanálise, acentuando a ideia de "impressão" da estranheza causada no sujeito e salientando a "ambiguidade" como marca do fantástico relativamente à transposição e à perceção do real. Para Louis Vax (1960: 5-6), o agenciamento fantástico distingue-se daquele que é utilizado pelo maravilhoso, na medida em que este último apresenta um mundo fora do real onde o impossível deixa de existir, enquanto o fantástico se nutre dos conflitos entre o real e o impossível.

Inserindo-se no contexto estruturalista dos anos 70, a teorização de Tzvetan Todorov (1970) visa captar um agenciamento específico e criar destrinças relativamente a outros géneros como o maravilhoso ou o estranho. Ao criar estas divisões, Todorov encara o fantástico como um género, limitando-o a determinada caracterização. Mas, as reações não tardaram e cedo foram apontados alguns problemas decorrentes do estreitamento de conceptualização do fantástico enquanto género, nomeadamente por Stanislaw Lem e, em certa medida, por Italo Calvino, no mesmo ano de 1970. Talvez não seja por acaso, aliás, o facto de estas críticas serem protagonizadas por dois escritores: enquanto criadores, ambos sentiram de certa forma o caráter mais espartilhado da teorização todoroviana.

As definições de Todorov carecem de ser situadas diacronicamente, ou seja, é necessário ter em conta que o seu posicionamento é estruturalista e que este posicionamento é posterior a abordagens de feição psicoanalítica, contrapondo-se, por exemplo, à teorização de Louis Vax que, em 1965, publicara La séduction de l'étrange. Étude sur la littérature fantastique. Ora, o investigador François Martin, quando tenta estabelecer o posicionamento diacrónico de diversas teorizações, nota que o fantástico era, para Louis Vax, a figuração de uma vã tentativa da parte do personagem/narrador de integrar o sobrenatural na esquematização do real. Mas, para além da vertente autoral, Louis Vax dá importância também, ao lado da receção do fantástico, ao chamar a atenção para as reações perante o que poderemos chamar o registo modal das ficções, ou seja, destaca a estranheza como elemento diferenciador quando chama a atenção para o sentimento de estranheza causado pelo fantástico, propondo assim a estranheza como elemento caracterizador do fantástico.

Surgindo depois e adotando uma perspetiva estruturalista, Todorov pretende estabelecer a diferença entre fantástico e estranho, mas, por isso mesmo, já não vai poder escolher a característica estranheza para estabelecer o que é fantástico e vai optar por outra condição: a hesitação. Segundo este teórico esta é a condição sine qua non para se poder classificar um texto como fantástico; porém, também este condicionamento, por ser demasiado estreito, tem sido alvo de contestação. 
François Martin, por exemplo, crê que o carácter fantástico se revela muito mais na justaposição do natural e do sobrenatural do que na hesitação.

Por sua vez, Eric Rabkin, que em 1976 publica o livro The Fantastic in Literature, no último capítulo da sua obra intitulado "The scope of the fantastic" afirma que, enquanto a Fantasy se pode apreender como género, o Fantástico tem um alcance alargado demais para ser considerado como tal (tal não quer dizer que este autor não seja influenciado por Todorov, sobretudo no que diz respeito à consideração da ambiguidade como um fator de diferenciação do fantástico).

Mais recentemente, Arnaud Huftier, no início da obra Les Frontières du Fantastique, aponta a apropriação indevida e imprópria que Todorov faz de textos que lhe são anteriores, ao passar por cima de problemas de tradução de certos termos de uma língua para a outra, de que é exemplo a tradução da palavra alemã unheimlich). Por outro lado, este crítico traça uma história da receção da obra de Todorov - um verdadeiro fenómeno de tradução rápida em várias línguas - e mostra como os teóricos seguintes perpetuaram algumas incorreções todorovianas.

Diferentemente, neste estudo perfilha-se um entendimento do fantástico não como género literário mas antes como uma qualidade ou predicado estético, alcançando assim uma dimensão modal mais abstrata com protocolos ficcionais específicos, tendo como interesse ver como se manifestam, nos casos concretos a abordar, as estratégias e os procedimentos que permitem acionar esses protocolos específicos. Pretende-se perscrutar como ao acionar estes procedimentos os autores alcançam uma subversão de sentidos que é apreciada pelo leitor.

De facto, para L. Armitt, "agora podemos olhar para o fantástico como uma forma de escrever que abre espaços subversivos dentro da fantasia, em vez de a levar para um gueto que a empacotasse dentro de géneros" (Armitt 1996: 3). Neste processo de resistência a um reducionismo genológico, o fantástico "mantém propriedades subversivas importantes sem capitular a uma classificação” (ibidem). Ressalta, então, o interesse de observar a maneira como o fantástico põe em causa a delimitação de fronteiras genológicas, axiológicas e outras. Salientando o poder subversivo do fantástico, L. Armitt afirma:

Em essência, aí onde as definições de género tendem a encerrar os textos, o fantástico abre-os a uma ambivalência que conspira contra as fórmulas [...]. Estes textos indefinidamente abertos e não-contidos dentro de fronteiras levantam uma perigosa ameaça às noções de conformidade e fixidez, uma característica que obviamente torna o fantástico uma apelativa forma para a exploração da marginalidade socio-política e da ex-centricidade. (Armitt 1996: 33).

Neste sentido, esta conceção situa-se no polo oposto à opinião de Filipe Furtado (1980: 101), o qual afirma que "nenhuma subversão importante é de esperar de qualquer dos comedidos protagonistas da ficção fantástica”. Contrariamente, o que Lucie Armitt resgata como interessante na teorização de Todorov reside, precisamente, na apreensão desta transgressão tal como Michel Foucault a define: "Transgressão é uma ação que envolve o limite [...]" (apud Armitt 1996: 33). 


\section{Narradores e narratários}

Amiúde se tem chamado a atenção para uma estratégia frequente do relato fantástico: a apresentação de um narrador que conta a história a um narratário (ou a mais do que um) e que, ao contar, o faz de forma a instaurar um grau maior de credibilidade relativamente a uma história inverosímil. Trata-se, na verdade, de uma estratégia que não é exclusiva do fantástico e que também não é condição sine qua non, pois não está presente em muitos relatos fantásticos. Embora tenha sido muito utilizada pelos escritores românticos, este é um procedimento que, em termos genéricos e sem atender às múltiplas variantes, remonta a narrativas tão antigas quanto as das Mil e uma noites. Se essa estratégia surge com frequência no relato fantástico, é porque este, apresentando uma história insólita, carece mais de acentuar o processo de make-believe apelando ao "acreditamento mútuo" de que fala Kendall Walton, ou seja: é dependente de um protocolo ficcional diverso do protocolo realista, uma vez que lida com o irreal.

Segundo Michel Vignes (2006: 16), diferentemente de uma conceção intelectualizante do fantástico (seja ela de hermenêutica mental, seja de interpretação psicanalítica), há uma outra conceção do fantástico que destaca a sua visualidade. Nesta linha teórica, onde se destacam Charles Grivel e Denis Mellier, chama-se a atenção para a capacidade de "mostrar" do fantástico e para dar a ver o inexplicável.

Entre os contos que ilustram estes aspetos, avultam aqueles que exploram o motivo do "déjà vu", como acontece na narrativa "O encontro" de Lygia Fagundes Telles, onde a personagem, embora repita para si mesma "nunca estive aqui", vai reconhecendo o bosque por onde caminha. De acordo com a narradora e protagonista, o que recordava "escapava à inconsistência do sonho", impunha-se-lhe através da minúcia da paisagem, vendo-se ela misteriosamente impelida a avançar "por uma força que não sab[e] de onde vem" e a ter de "aceitar o inexplicável" (Telles 1981: 69). Encontra uma amazona de trajes antigos que demora a reconhecer, mas que finalmente, num crescendo de tensão emocional, reconhece ser ela própria.

Defende-se aqui que, para esta exibição do inaceitável (de um ponto de vista realista), concorre, em muito, a estratégia de expor a narração mostrando um narrador que, por sua vez, mostra o que viu (ou experienciou).

No conto "A visão de Catherine"1, Sheridan Le Fannu aciona esta estratégia, pois é a Senhora Fanshawe que vai contar a história de Catherine, uma amiga da sua filha que é recebida como visita durante as férias do Natal, depois de a família se ter mudado para a antiga "mansão de Craymoor Grange”. A narradora assume que está a fazer um relato, como se pode ver na seguinte frase: "Dado que a minha história é, sobretudo, sobre Catherine l'Estrange, creio que devo falar um pouco mais sobre ela." A analepse serve para enquadrar melhor a personagem; todavia, a narradora assume não saber muito sobre a família de Catherine - o que permite manter o suspense. Só depois de uma breve analepse, a narradora regressa à narração dos elementos centrais, afirmando: "E agora, após um longo e receio que entediante preâmbulo, darei início à minha história." Porém, quando se chega ao episódio fulcral da assustadora visão que Catherine tem, num quarto antigo com uma grande janela em arco entaipada, será a própria Catherine a narrar o episódio. Nessa

1 Não havendo traduções recentes em Portugal dos contos de Le Fanu, optou-se aqui por recorrer às traduções realizadas por João Luís Moreira, em 2011, disponíveis online. 
visão, a personagem vê os seus antepassados - a família l'Estrange do séc. XVII - dominados por uma malvada mulher, e vê como foram cometidos dois crimes de homicídio e um crime de usurpação de bens. Ou seja: há uma narração encaixada dentro da principal, com uma narradora diferente que tem a sua própria audiência: a família Fanshave e os amigos que recebem na mansão Craymoor Grange. Como se de uma encenação se tratasse, representa-se, em mise en abyme, o próprio ato de narrar, ao qual o leitor assiste ao lado das personagens. A visão de Catherine permite encontrar a arca onde estão os ossos das vítimas e também o testamento - que é a peça fundamental para a progressão da intriga.

Este conjunto de procedimentos elucida a ideia expressa por Louis Vax (1965: 129) de que "não há fantástico sem situação fantástica”, pois o fantástico "possui a sua própria verdade, a sua própria verosimilhança, a sua própria ilusão", as quais fazem um pastiche da verdade e a "desfiguram”. As diversas narradoras, a estratégia de encaixe, os rebondissements da ação através de objetos como o testamento ou a carta da tia de Catherine, a referência aos objetos herdados e, entre eles, o colar que Catherine vira durante a sua visão - são estratégias que permitem instaurar a situação da fantástica visão da personagem.

Também no conto "A estrela branca" o protagonista se assume como narrador ao afirmar, repetidamente, que "quer contar tudo". Como o conto começa com a expressão “Ah, meu Deus!" e o protagonista está prestes a suicidar-se, é provável que o narratário seja Deus, constituindo assim a narração uma espécie de confissão da veleidade do próprio protagonista, de querer voltar a ver depois de ter ficado cego.

Porém, neste conto não se verifica aquele encenar do contexto situacional da narração observável no conto anterior - apenas se encontra o protagonista como narrador de primeira pessoa, frequente nos relatos fantásticos.

Por sua vez, o conto "As noites da Condessa Bruni" de Rui Herbon também apresenta uma situação particular de narração: o tio Joshua McNaughton, "luminária de Harvard", "delfim da prosa de Henry James”, conta ao sobrinho como conheceu em Itália a Condessa Bruni, uma jovem mulher que o fascinou e com quem saiu, mas que, em poucas horas, se tornou muito velha. Com todo o cuidado para que a Tia Alice não oiça a perturbadora história e com a exceção de algumas interrupções vindas da sala, a narração é feita na intimidade do escritório, numa espécie de passagem de testemunho de tio para sobrinho. Tratar-se-ia de uma situação normal, não fora o facto de, no final do conto, o narratário pretender partir para Itália à procura da mesma estranha Condessa, com o intuito de experienciar também a loucura de acompanhar uma mulher que envelhece anos em minutos. Este ressalto final, quando o leitor julgava a narrativa terminada, acaba por conferir credibilidade à narrativa inicial: se o sobrinho acredita... então, o poder de sedução do narrador teve o efeito pretendido - a sua narração foi acreditada, abrindo a possibilidade da sua repetição e uma futura hipótese de mise en abyme.

\section{Dessintonia do espaço-tempo}

Diversos são os jogos com o tempo explorados pelo fantástico, como já salientou David Roas na sua proposta de "catalogação de diversas formas de transgressão fantástica da temporalidade convencional” (Roas 2012: 107). 
Entre os vários jogos temporais elencados por David Roas contam-se, por exemplo, o "tempo expandido", os "tempos convergentes", a "entrada noutro tempo". Este último procedimento é fundamental na ficção científica, mas também surge em textos fantásticos, como é o caso do conto "O Manuscrito Lorenzetti” de Rui Herbon que combina, de maneira aliciante, este procedimento com uma reelaboração do mito fáustico, pois apresenta a história de um pintor do séc. XV, amigo de Leonardo da Vinci, que vende a alma ao Diabo para saber se terá algum dia um lugar na história da arte e se será famoso no futuro. O Diabo concede-lhe uma visita ao Museu do Louvre no séc. XX, repleto de visitantes nossos contemporâneos, onde o seu desejo irá ter resposta, a qual, todavia, pagará com a sua alma. A genialidade deste conto reside na mudança do tema da "eterna juventude", convocado no mito de Fausto, para o tema bem contemporâneo da sobrevida pela fama. Para que o pintor possa ver melhor, o Diabo detém o tempo, ficando todos os visitantes suspensos no passo que davam - alia-se assim o procedimento da "entrada noutro tempo" com o do "tempo suspenso" (Roas 2012: 110).

Já o conto "As noites da Condessa Bruni" sugere um “tempo cíclico", já que o protagonista deseja ser um émulo do tio e anseia por partir à procura da Condessa ferozmente atingida pela voracidade do tempo. Se o crítico David Roas, ao proceder à discriminação das várias formas de transgressão temporal, afirma que se trata de uma listagem aberta, este conto poderá apontar para mais uma forma transgressora do tempo: o "tempo a diferentes velocidades".

Por seu turno, o conto de Sheridan Le Fanu pode inserir-se também na forma da "entrada noutro tempo", já que, na sua visão, a protagonista consegue ver os antepassados de há três séculos atrás.

Já no caso do conto de Lygia Fagundes Telles, a questão temporal que se coloca tem a ver com a perda da noção da passagem do tempo, no período em que o cego espera, no hospital, pela operação que o curará, o que não seria, em si, insólito - apenas ganha em estranheza quando conjugado com a perda de controle da personagem sobre si própria.

\section{Corpo, metamorfose e morte}

Entre os diferentes eixos explorados pelo fantástico, um deles diz respeito ao corpo e às suas possíveis alterações. Nos textos fantásticos encontram-se frequentemente mortos-vivos, fantasmas, criaturas disformes dos mais diversos feitios, sendo a metamorfose corporal um dos recursos compositivos de tal modo importante que Jean-Luc Steimetz, um dos mais notáveis críticos do fantástico, considera a metamorfose "o tema dinâmico mais eficiente do mundo fantástico" (Steimetz 1990: 31).

$\mathrm{Na}$ maior parte das vezes, as alterações no corpo estão ligadas ao macabro, ao horrífico e ao grotesco, suscitando o horror, o terror e o medo. Mas as alterações corporais também podem ser encaradas de modo menos dramático e olhadas apenas na sua estranheza, tendendo a dissolver o seu caráter insólito na banalidade do quotidiano.

Também aqui podemos notar semelhanças e diferenças nos contos dos três autores em apreço. No conto de Sheridan Le Fanu, os antepassados surgem como fantasmas (os da visão de Catherine); mas, para além disso, as personagens maléficas são apresentadas com um "rictus" perverso e com um traço maligno que as liga, explícita ou implicitamente, a um sobrenatural demoníaco. 
Assim, a "dama cruel" do conto "A visão de Catherine" é uma dama "alta e de meia-idade, e seria bela não fossem os olhos escuros e luzentes naquele rosto sinistro, realçados pelas escuras sobrancelhas que os toldavam". Estes dois pormenores - o dos olhos escuros e luzentes e o do sorriso sinistro - bastam para compor fisicamente o desenho ominoso da personagem, completando-se o retrato com a característica psicológica da crueldade. A negrura dos cabelos, das sobrancelhas e sobretudo o negro luzente dos olhos colocam a personagem do lado do mal e sob a alçada do rei das trevas.

Além das personagens malévolas há ainda, neste conto, o lado macabro do homicídio, com duas personagens enterradas vivas, sendo Agatha Tornhough, a "dama cruel", o algoz do primeiro crime e a vítima do segundo, na condição agravada de ser fechada junto do cadáver da sua vítima, ou seja, junto do "cadáver em decomposição da jovem" que matara. Por antever o seu destino, "os olhos da dama cruel acenderam-se por um segundo com o pavor da morte", mas logo "os seus gritos [foram] abafados para sempre sob a tampa maciça”. Trata-se, portanto, de um conto que explora a tafofobia, ou seja, o medo ancestral de ser enterrado vivo.

Através da visão, os mortos readquirem corpo e mostram as suas feições. E tudo isto caberia apenas na dimensão onírica pressuposta na visão fantasmática da protagonista, não fora o facto de se encontrarem os ossos das duas mulheres, mortas há duzentos anos, quando Catherine pede para abrirem a arca. Nela encontrarão também o testamento da família l’Estrange, que poderá reinstaurar Catherine como herdeira da mansão de Craymoor. Os esqueletos são, pois, para as personagens, a prova da existência dos corpos e da degradação do ser, passando pela horrífica fase intermédia da decomposição do corpo.

De um esqueleto também trata o conhecido conto "As formigas" de Lygia Fagundes Telles, embora aqui não saibamos o que finalmente acontece ao esqueleto. O corpo, porém, está presente ainda que por omisubsussão, pois a estudante de medicina identifica o conjunto de ossos como pertencendo a um anão. O fantástico surge através do animismo das formigas que adquirem vontade própria para montar o esqueleto que a pouco e pouco vai ficando encaixado na ordem certa. Este conto tem sido muito abordado em trabalhos de crítica literária, não só porque se trata de um conto com um muito conseguido suspense, mas também pelo seu final suspendido, ou seja, pela incerteza e o seu carácter inconclusivo - característica que faz com que este conto seja facilmente subsumível à categoria do fantástico dentro das distinções teóricas todorovianas. Com efeito, este é um conto que explora a hesitação - elemento que Todorov defende ser a característica sine qua non do fantástico. Concomitantemente, este conto explora também o efeito do medo - outra característica que para muitos críticos é a condição mais importante do fantástico - que aqui se relaciona diretamente com a disformidade corporal específica do nanismo que, pela estranheza e pela diferença, apresenta, em várias culturas, um longo historial de ligação com as forças do mal.

Por seu turno, no conto "A estrela branca" de Lygia Fagundes Telles, a questão do corpo adquire ainda mais relevância, dado que o corpo e, em particular, os olhos constituem o cerne da narrativa: a cegueira surge como a anomalia do corpo que o médico diz poder remediar e assim o faz ao substituir os olhos do cego por uns de um vagabundo às portas da morte. Porém, quando finalmente consegue ver, o ex-cego verifica aterrado que os novos olhos não lhe obedecem, permanecendo com a vontade do seu antigo dono que, de modo metempsicótico, persiste no novo corpo através dos olhos - uma situação, aliás, ominosamente anunciada pelo morrente vagabundo. A disfunção corporal relativa à visão é o motivo condutor deste texto, fazendo emergir o tema 
da dissociação do eu e da duplicidade que, numa leitura mais psicologizante, pode representar o medo da alteridade e o medo de reconhecer o outro em nós.

Diferente é o tratamento do elemento corporal no conto de Rui Herbon. O facto de a Condessa Bruni envelhecer de forma galopante é apresentado como um tipo de insólito aberrante que, curiosamente, não é desencadeador de medo ou de repulsa, mas sim de atração mórbida - uma atração movida por uma curiosidade fatal, mais sensualista que masoquista, pois dá ao narrador a hipótese de assistir ao "espetáculo do imparável transcorrer de todas as idades" da condessa, "saboreando aquela metamorfose numa calma completa" (Herbon 2013: 79). Toda a metamorfose da Condessa Bruni é marcada pelos sinais do envelhecimento: as carnes que se tornam flácidas, a pele que enruga, o cheiro que se modifica. Este conto lida, pois, com um dos nossos medos mais antigos e comuns: a gerascofobia, ou o medo de envelhecer.

\section{O duplo e duplicação}

Se o tema do duplo não se manifesta no conto "A visão de Catherine", de Sheridan Le Fanu, já não está completamente ausente no conto "A Dívida de Honra”, pois aqui encontramos uma duplicação no episódio em que o Sr. Maryon joga às cartas com Geoffrey Ringwood, sendo a aposta a propriedade "The Mere". Exaltado por ter perdido, John Maryon luta com o seu adversário acabando por o matar; anos depois, o fantasma do morto, atormentando o seu assassino vem repetir o mesmo jogo e a mesma situação com ele - que, em ataques de sonambulismo, repete o jogo. O motivo do duplo, segundo Michel Vignes (2006: 187), representa a consciência moral atuando como um superego, uma função desempenhada pelo fantasma de Geoffrey Ringwood, neste conto de Le Fanu. Com efeito, John Maryon confessa-se assombrado pelo crime que cometeu, e o fantasma do assassinado que, para grande susto do protagonista, era uma figura que "não deixava pegadas na neve", fá-lo reviver a noite do crime à laia de expiação.

Mais evidente se apresenta a duplicidade enquanto motivo tradicional do fantástico no conto "A estrela branca" de Lygia Fagundes Telles, uma vez que o cego recomeça a ver com uns olhos que não lhe obedecem. Se, aqui, o duplo cumpre a função de "representa[r] a parte obscura da psyche” apontada por Michel Vignes (2006: 186), não é a parte obscura da mente do protagonista, mas sim do homem em geral, uma vez que o vagabundo aparece não só como um indivíduo sujo exteriormente, mas também perverso e mau. A dissociação apavorante entre o homem senhor de sua vontade e os novos olhos com uma vontade alheia coloca o tema do duplo como o ponto nuclear da narrativa, dando-lhe uma clara dimensão fantástica com laivos de ficção científica, uma vez que foi através de uma operação ainda hoje impossível (realizada pelo estranho médico Ormúcio) que o cego voltou a ver.

No seio da mesma linha temática, cabe ainda referir o breve conto da mesma autora intitulado "O encontro" em que a protagonista, estranhamente atraída para um bosque, encontrou uma dama de tempos idos, a cavalo, cuja aparência a galvaniza sem perceber porquê, até que, depois de várias cenas do passado acudirem à sua memória, reconhece ser ela própria, balbuciando “- Eu fui você". A crer que a cavaleira se "despenca no abismo" (Telles 1981: 73-74), a protagonista apenas existe por transmigração de almas, sendo apenas possível este encontro com o seu "eu" antigo na ordem do fantástico, que gera a possibilidade de cruzar dois tempos diferentes. 
Por último, resta dizer que, no conto de Rui Herbon, o tema da duplicidade também surge, embora não se verifique pela duplicação do protagonista, mas sim pela sugestão da inusitada experiência com a Condessa Bruni se poder duplicar passando do Tio ao sobrinho.

\section{Inferências}

Que ilações poderemos retirar desta abordagem comparativa? Primeiramente, a noção de que existem elementos e temas do fantástico que são recorrentes, mas que apresentam matizes e efeitos muito diversos. Alguns destes elementos acionam efeitos diversos que vão desde o terror à mera surpresa, desde a angústia à curiosidade.

Privilegiou-se, nesta análise, uma abordagem realizada a partir dos elementos e das estratégias utilizadas para acionar este registo, atendendo, por vezes, às emoções provocadas. Os motivos explorados aqui evidenciam essa capacidade de "mostrar", para a qual vários teóricos chamaram a atenção. Charles Grivel afirma que o fantástico "é um efeito de écran (de tela). Esta tela está primeiramente nos olhos de quem olha. A seguir, é projeção mental sobre um véu brilhante" (Grivel 1992: 187). Salienta, portanto, a parte de espetáculo com que o fantástico se apresenta ao público. Viu-se como isto se processa através das estratégias de encenação da narração que, por sua vez, apelam ao olhar e à visualidade, tal como se torna evidente com a "presença" das manifestações corporais - como o fantasma, a aparição, a metamorfose e a duplicação. Por isso, Alain ChareyreMejan afirma que "toda a impressão sensível é ela mesma a impressão da existência de um real, uma vez que não há impressão na ausência dos termos. O fantástico dos nossos monstros é o real das nossas impressões" (Chareyre-Mejan 1999: 33).

Na mesma senda investigativa, Denis Mellier afirma que "os mundos da ficção fantástica tendem a hiper-realizar a ficção. Assim, estes mundos, na sua visibilidade, o explícito e o paroxismo, objetivam a possibilidade da ficção ela mesma e da sua emoção" (Mellier 1999: 427). De acordo com a teorização deste autor, é possível perceber tanto a vertente "mostradora" ("monstration"), hiper-realista do fantástico como a sua vertente de "indeterminação" e de "ambiguidade".

O que se pode observar através da análise das narrativas dos três autores, em certa medida representativos de períodos históricos diferentes, é, por um lado, um acentuar progressivo da indeterminação e, por outro lado, a preferência por uma integração dos elementos fantásticos "mostrados", tornados "presentes" numa representação do quotidiano contemporâneo (ou uma conjugação dos dois procedimentos). Repare-se que não há a substituição de um tipo de fantástico por outro, mas antes uma modulação diversa, deixando ver a heterogeneidade dos textos fantásticos.

Tome-se como exemplo da primeira situação - o acentuar da indeterminação - a personagem Dr. Ormúcio do conto de Lygia Fagundes Telles. De forma mitigada ele é um avatar do Dr. Jekyll, mas o conto aproxima-se muito mais da crença contemporânea de que a medicina pode resolver todas as deficiências, pode eliminar as anomalias e pode consertar o corpo, salientando, para além disso, a perversidade de um vagabundo que simboliza a maldade no plano social e também a maldade que existe em cada um de nós. Nesta mesma senda, o conto "O encontro" pode simbolizar a dificuldade que temos em lidar com o nosso passado, mas também a relutância de nos confrontarmos com decisões que tomámos em determinado momento do passado (decisões escultoras de nosso presente) e ainda o confronto connosco, ou seja, do 'eu' consigo próprio. 
Cumpre-se, assim, aquele alargamento do indizível ao indeterminado que, segundo Denis Mellier (1999: 121), se funda na impossibilidade de construir um jogo de hipóteses onde esse mesmo jogo não seja posto em dúvida.

Diferentemente, o caso do conto "O Manuscrito Lorenzetti" de Rui Herbon explicita a segunda situação, pois nele se joga essa estratégia de um fantástico dirigido ao olhar e que se "mostra", pois surge a velha figura do diabo tentando o homem. Porém, este diabo torna-se muito banal, inserido numa representação realista, ao permitir ao protagonista o salto para um mundo contemporâneo de uma visita ao Louvre que todos nós podemos fazer. O fantástico exibe-se, aqui, pelo seu caráter excessivo quando integrado na banalidade. Assim, mesmo utilizando elementos sobrenaturais como o diabo (ou fantasmas, ou aparições, etc.) este fantástico também se modalizou e se modificou.

Com efeito, no conto "O Manuscrito Lorenzetti", o diabo, ainda que postulado como uma figura sobrenatural, aparece aos dois amigos pintores Francesco Lorenzetti e Leonardo da Vinci com uma presença de intensa normalidade: "O homem vestia roupas baratas e não havia nada de excecional no seu rosto nem na sua figura." Aduz-se ainda que era um "homem pouco ou nada memorável, fácil de confundir com tantos outros" (Herbon 2013: 17). Somente quando vê os seus olhos, que faziam estremecer pela sua singularidade, percebe a dimensão arquetípica: eram olhos que podiam ficar "acesos como fogueiras". Apenas os olhos levam o pintor a perceber que a propositada banalidade "só podia ser uma máscara". Mas, para que não restem dúvidas aos dois amigos pintores, o diabo faz parar o tempo por alguns segundos. Moderniza-se assim a presença do diabo e do mito fáustico com o motivo da viagem no tempo e com o efeito da paragem do tempo - um efeito muito cinematográfico, pois se dá a ver o movimento "congelado" através de uma imagética figurativa e espacial estática, em contraste com a continuação do movimento e da temporalidade relativamente às personagens principais, ou seja, os dois pintores e o próprio diabo.

A visualidade do fantástico continua a manifestar-se no conto através do movimento de travelling no Museu do Louvre, quando Lorenzetti vai à procura dos seus quadros e só encontra um que ele de certa forma (re)conhece: "A Gioconda" que, sob uns cabelos de mulher, reproduzia o seu rosto. A preocupação com a imortalidade e a fama (em contraste com a atitude de "viver para o presente" escolhida e aconselhada por Leonardo) domina a personagem; mas ela foge-lhe quando chega a alcançá-la, pois não só o talento que é aplaudido é o do seu amigo e não o seu, como, para além disso, o seu rosto ligado à sua própria personalidade que servira de modelo à representação não coincide com o rosto representado de mulher. Este ser e não ser famoso, ou melhor, o ser famoso deixando de ser ele próprio põe em causa aquilo que o pintor valoriza como sentido da vida: procurando a fama, o sujeito apenas se encontra sob uma outra máscara. Ser e não ser ele é, assim, uma forma de estranhamento de si próprio conduzindo o sujeito ao autoquestionamento do "sentimento de si".

O fantástico e o estranho ganham, assim, uma dimensão existencialista (cf. Masschelein 2011: 137), pondo a descoberto a nossa alienação e o desconhecimento de nós mesmos. Na verdade, como G. Deleuze e F. Guattari (1980: 206) destacaram, "O rosto não é um envelope exterior àquele que fala, que pensa ou que sente." O rosto não existe por si, mas sim em relação a espaços-tempos, afetos, frequências, etc. Para estes filósofos, "a forma da subjetividade, consciência ou paixão, per- 
maneceria absolutamente vazia se os rostos não formassem lugares de ressonância que selecionam o real mental ou sentido."

A máscara, o duplo, a metamorfose (mais que outros procedimentos) chamam a atenção para esta pregnância do rosto (ou a falta dela). Ora, a análise dos contos abordados permite inferir que, quanto mais as narrativas se aproximam da nossa contemporaneidade, mais exploram e aprofundam a complexidade dos efeitos de ressonância referidos pelos dois filósofos, repercutindo os sentidos relacionais do sujeito numa sociedade em rede.

\section{Referências bibliográficas}

Armitt, L. (1996). Theorising the Fantastic. London / New York: Arnold.

Bozzetto, R.; \& Huftier, A. (2004). Les Frontières du Fantastique. Approches de l'impensable en littérature.

Valenciennes: Presses Universitaires de Valenciennes.

Chareyre-Mejan, A. (1998). Le Réel et le Fantastique. Paris: L’Harmattan.

Deleuze, G.; \& Guattari, F. (1980). Mille plateaux. Paris: Les Éditions de Minuit.

Furtado, F. (1980). A Construção do Fantástico na Narrativa. Lisboa: Livros Horizonte.

Grivel, C. (1992). Fantastique-fiction. Paris: PUF.

Herbon, R. (2013). O Prazer dos Estranhos. Lisboa: Edições Colibri.

Le Fanu, S. (2011). A visão de Catherine. In J. L. Moreira. Narrativas Góticas de J.S. Le Fanu: Uma proposta de tradução. Dissertação de Mestrado. Lisboa: Faculdade de Letras da Universidade de Lisboa <http:// repositorio.ul.pt/bitstream/10451/6946/1/ulfl111684_tm.pdf>

Martin, F. (2008). Entre le dogme et le doute: figures réligieuses et dimension cognitive dans la nouvelle fantastique québecoise avant et aprés la révolution tranquile. Mémoire de Maîtrise présentée à l'Université du Quebe à Trois Rivières. <http://depot-e.uqtr.ca/1362/1/030045949.pdf>

Masschelein, A. (2011). The Unconcept: The Freudian Uncanny in Late-Twentieth-Century Theory. Albany (NY): State University of New York Press - Suny Press.

Mellier, D. (1999). L'écriture de l'excès. Fiction fantastique et poétique de la terreur. Paris: Editions Champion. Moreira, J. L. (2011). Narrativas Góticas de J.S. Le Fanu: Uma proposta de tradução. Dissertação de Mestrado, Lisboa: Faculdade de Letras da Universidade de Lisboa. <http://repositorio.ul.pt/bitstream/10451/6946/1/ ulfl111684_tm.pdf>

Rabkin, E. (1976). The Fantastic in Literature. Princeton: Princeton University Press.

Roas, D. (2012). Cronologías alteradas. La perversión fantástica del tiempo. In F. García, \& N. C. Batalha (Orgs.), Vertentes teóricas e ficcionais do Insólito (pp. 106-113). Rio de Janeiro: Editora Caetés.

Simões, M. J. (2007). O Fantástico como catégoria estética: as diferenças entre os monstros de Ana Teresa Pereira e Lídia Jorge. In M. J. Simões (coord.), O Fantástico (pp. 65-81). Coimbra: Centro de Literatura Portuguesa.

Steimetz, J.-L. (1990). La littérature fantastique. Paris: PUF.

2 Na versão francesa: "Le visage n’est pas une enveloppe extérieure à celui qui parle, qui pense ou qui ressent. (...) La forme de la subjectivité, conscience ou passion, resterait absolument vide si les visages ne formaient des lieux de résonnance qui séleccionnent le réel mental ou senti” (Deleuze e Guattari 1980: 206). 
Telles, L. F. (1981). Mistérios. Rio de Janeiro: Editora Nova Fronteira.

Todorov, T. (1970). Introduction à la littérature fantastique. Paris: Seuil.

Vax, L. (1960). L'art et la littérature fantastiques, Paris: PUF.

- (1964). La séduction de l'étrange. Étude sur la littérature fantastique. Paris: PUF.

Walton, K. (1990). Mimesis as Make-Believe. On the Foundations of Representational Arts. Cambridge, Massachusetts/London: Harvard University Press.

Vignes, M. (2006). Le fantastique. Paris: G. Flammarion. 